\title{
Physical activity and barriers and facilitators in patients with rheumatoid arthritis or spondyloarthritis: a cross-sectional study of 150 patients
}

\section{Thomas DAVERGNE ( $\square$ thomas.davergne@gmail.com )}

iPLESP: Institut Pierre Louis d'Epidemiologie et de Sante Publique https://orcid.org/0000-0001-78690062

\section{Rawdha Tekaya}

University of Tunis El Manar: Universite de Tunis El Manar

\section{Jérémie Sellam}

Sorbonne Universite Faculte de Medecine Campus Saint-Antoine

Anne Tounadre

University Clermont Auvergne: Universite Clermont Auvergne

\section{Stephane Mitrovic}

Institut Mutualiste Montsouris

\section{Adeline Ruyssen-Witrand}

University Hospital Centre Toulouse: Centre Hospitalier Universitaire de Toulouse

\section{Christophe Hudry}

Sorbonne Université: Sorbonne Universite

\section{Sabrina Dadoun}

Ramsay Générale de Santé: Ramsay Generale de Sante

\section{Jérôme Avouac}

Hospital Cochin Rheumatology Institute: Hopital Cochin Institut de Rhumatologie

\section{Bruno Fautrel}

Hopital Universitaire Pitie Salpetriere Service de rhumatologie

\section{Laure Gossec}

Hopital Universitaire Pitie Salpetriere Service de rhumatologie

\section{Research article}

Keywords: Barriers and facilitators, Physical activity, Axial Spondyloarthritis, Rheumatoid Arthritis, Psoriatic Arthritis, Patient reported outcome measures 
DOl: https://doi.org/10.21203/rs.3.rs-548185/v1

License: (c) (1) This work is licensed under a Creative Commons Attribution 4.0 International License. Read Full License 


\section{Abstract}

\section{Background}

Barriers and facilitators to physical activity in inflammatory arthritis can be assessed through the Inflammatory arthritis Facilitators and barriers questionnaire (IFAB) questionnaire. The objective was to measure the correlation between IFAB and self-reported physical activity levels.

\section{Methods}

This was an international, multicentric, cross-sectional study in 2019-20 (NCT04426747). Consecutive spondyloarthritis (axSpA), rheumatoid arthritis (RA) or psoriatic arthritis (PsA) patients completed the 10item IFAB, ranging - 70 to 70 with lower scores indicating more barriers. Physical activity was measured by the IPAQ-S questionnaire, steps per day collected by smartphone, and psychological readiness to change by stages of behavior change. Spearman correlations and multivariable linear regression were calculated.

Results

Of 245 patients included, 150 were analysed: 69 (46\%) axSpA, 63 (42\%) RA, 18 (12\%) PsA. Mean age was 48.6 years (standard deviation, SD 17.1), mean disease duration 11.7 (10.1) years and 60\% were women. Barriers to physical activity were moderate: mean IFAB, 6 (SD 19.2); 39 (26\%) patients scored less than 5, corresponding to significant barriers. The mean physical activity was 2837 (SD 2668, median 1784) MET-minutes per week. Physical activity was correlated with the IFAB (rho $0.28, p<0.001$ ), as well as the stage of behavior change (rho $0.35, p<0.001$ ) though not with steps per day. Multivariable analyses were confirmatory.

\section{Conclusion}

Perceived barriers and facilitators to physical activity were correlated with physical activity, indicating that targeting patients with high barriers and low facilitators to physical activity could be an effective option to improve physical activity levels.

Trial registration on ClinicalTrial

NCT04426747. Registered 11 June 2011 - Retrospectively registered, https://clinicaltrials.gov/ct2/show/NCT04426747

\section{Significance And Innovation}

- Patients with inflammatory arthritis are more prone to physical inactivity than the general population but derive specific benefits from regular physical activity. 
- In this study, a majority (67\%) of patients with inflammatory arthritis reported a low to moderate level of physical activity and only $27 \%$ reached the recommended amount of physical activity by 7,000 steps per day.

- In this population of 150 patients with inflammatory arthritis, a link was observed between a global score of barriers and facilitators and physical activity levels collected through IPAQ-S.

- This questionnaire could be a practical tool to use in clinical practice and in research to address perceived barriers and facilitators to physical activity in order to increase the physical activity levels of patients with inflammatory arthritis.

\section{Introduction}

Physical inactivity has been identified as the fourth leading risk factor for global mortality around the world[1]. The positive effects of physical activity on health, wellness and reduced mortality are widely established and documented for all ages[2-5].

Patients with inflammatory arthritis (IA), such as axial spondyloarthritis (axSpA), rheumatoid arthritis (RA) or psoriatic arthritis (PsA) are more prone to physical inactivity than the general population[6, 7]. Patients with IA derive specific benefits from regular physical activity[8-10]. In addition, patients with IA are at risk of other co-morbidities such as cardio-vascular diseases which can also be positively influenced by physical activity[11, 12]. Increasing physical activity in IA patients is a challenge[13]. Lifestyle changes should be addressed by a global approach taking into account behavioral barriers to increase chances of success[14].

Barriers and facilitators to physical activity are key elements to understand physical activity behavior in rheumatic diseases[15-18]. These elements can be classified as symptoms of the condition, social or physical environment of the person, and/or psychological status[19]. A Questionnaire for Inflammatory arthritis patients assessing FAcilitators and Barriers to physical activity (IFAB) has been recently developed and validated in patients with IA[20]. The relevance of a score to assess barriers and facilitators would be increased if a link was shown with physical activity behaviors. Such a link would allow to consider alternative and enhanced approaches to physical activity assessment and interventions. Previous studies sought to determine which factors influence physical activity levels in patients with IA. They showed a link between physical activity and general or arthritis-specific barrier limitations but without considering a global score including barriers and facilitators[21-23].

The objective was to measure the correlation between barriers and facilitators, assessed through the IFAB questionnaire, and self-reported physical activity levels. We also explored other markers of physical activity, through stages of behavior change and steps per day indicated by smartphones.

\section{Patients And Methods}

\section{Study design}


The ImBAIA study was an international, multicentric, cross-sectional study in a usual-care setting, performed in secondary and tertiary care hospitals in France (10 centres) and in Tunisia (one centre), between October 2019 June 2020 (ClinicalTrial NCT04426747)[24]. This study was approved by the ethics committee (CPP Sud-Est III, France, EudraCT 2019-A01413-54, methodology MR03 for noninterventional studies). All patients received at inclusion oral and written information, and oral consent was obtained. This report followed the STrengthening the Reporting of OBservational studies in Epidemiology (STROBE) statement[25].

\section{Participants}

Inclusion criteria were: age above 18 years; definite IA confirmed by the rheumatologist based on classification criteria: axSpA (referring to the Assessment of SpondyloArthritis international Society classification criteria)[26], RA (referring to the international classification criteria of RA)[27] or PsA (referring to the CIASsification of Psoriatic ARthritis (CASPAR) criteria)[28], with no restriction for comorbidities; ability to walk, having a smartphone compatible with apps that can track steps; ability to read and write in the language of the participating country.

Over the recruitment period, consecutive patients with definite axSpA, RA or PsA who satisfied the inclusion criteria, seen in outpatient visits by one of the investigators, were invited to participate.

\section{Outcomes collected}

\section{Barriers and facilitators to physical activity}

Barriers and facilitators to physical activity were measured through the IFAB questionnaire, validated in IA patients[20]. This questionnaire contains 10 items. The items are related to psychological status $(\mathrm{N}=6)$, social support $(\mathrm{N}=2)$, disease $(\mathrm{N}=1)$ and environmental factors $(\mathrm{N}=1)$. The total score ranges from -70 to 70 with a higher score indicating a higher level of facilitators and/or a lower level of barriers. Results below -5 were identified in the initial development as potentially justifying a targeted intervention[20].

\section{Physical activity behavior}

Different indicators of physical activity behaviors were used in this study.

Self-reported levels of physical activity were collected through the International Physical Activity Questionnaire Short form (IPAQ-S) and were analysed though the number of metabolic equivalent of task (MET) minutes per week (energy expended while performing various activities throughout the whole week)[29]. The level of physical activity was categorised as low, moderate and high following the IPAQ scoring protocol[30].

A simple question developed by the authors, assessing the feeling of doing enough activity was also used ("Do you think you do enough physical activity?") and was scored on a 0 to 10 numeric scale. 
Involvement in an active lifestyle was assessed through a questionnaire, the stage of behavior change regarding active lifestyle[31]. Active lifestyle is defined in this questionnaire as 150 minutes of moderate activity or 75 minutes of intense activity per week, according to the recommendation of the World Health Organisation[1]. Stage of behavior change ranges 1 to 5 , from precontemplation '(I do not engage in regular physical activity and do not intend to in the next 6 months') to maintenance ('I engage in regular physical activity and have been doing so for more than 6 months')[31].

The level of physical activity was also collected through mean daily steps per month on the last four full weeks through smartphone Apps, either installed by default (such as Health on iPhone or Samsung Health on Samsung) or installed by the patient (such as Runtastic or Fitbit)[32, 33]. The results were selfreported into the patient CRF. The threshold of 7,000 steps per day has been used as a recommended level of physical activity for patients with chronic disabilities[34]. The following classification was used to interpret steps per day: $<5000=$ sedentary, 5000-7499 = low active, 7500-9999= somewhat active, 10 000-12 499 = active and $\geq 12500=$ highly active[35].

\section{General data collected}

Other variables collected were socio-demographic data, as well as information about the underlying condition (type of IA, year of diagnosis of IA), current treatment and comorbidities, collected using the Functional Comorbidity Index ( $0=$ no comorbidity; to 18)[36]. In patients with RA: the Disease Activity Score 28 (DAS28) was collected using the last available data[37]. In patients with axSpA, disease activity was measured through the Bath Ankylosing Spondylitis Disease Activity Index (BASDAI) and through the Disease Activity Index for Psoriatic Arthritis (DAPSA) for PsA patients[38]. Function was measured via the modified Health Assessment Questionnaire (mHAQ). Physician global assessment was assessed on a numeric scale (0-10).

\section{Statistical analyses}

\section{Sample size calculation}

to demonstrate a link between the IFAB questionnaire score and IPAQ-S with a relative risk of $0.5,144$ patients were needed (with a 0.5 and $\beta 0.20$ ).

Descriptive statistics relied on mean (standard deviation, SD) and median values. The link between the IFAB and physical activity, using primarily the IPAQ-S, then exploring stage of behavior change and steps by smartphone, was tested using Spearman correlation. Both total score and individual items of the IFAB questionnaire were analysed.

Three multivariable linear regressions were performed, using as dependent variable the IFAB, and as explanatory variables, first IPAQ-S (MET-minutes per week) and the stage of behavior change. Mean daily steps per month was not used as explanatory variable because not linked with IFAB score in univariate analysis. Other variables were included in the models based on statistical association in univariate analysis $(p<0.20)$ and on their clinical relevance: these were: age, gender, disease duration, physician 
global assessment and number of comorbidities. For each analysis, assumptions regarding linearity, homoscedasticity, and normality were checked. The $\alpha$-level of significance was set at 0.05 .

The coherence of the 3 physical activity behaviors measures was assessed by the correlation or t-test between the IPAQ-S score and mean daily steps per month, stage of behavior and binary feeling of enough activity.

Statistical analyses were performed using $\mathrm{R}$ version 3.5.1. There was no imputation of missing data. However, for mean daily steps per month on the smartphone, a correction was applied for outliers.

\section{Results}

\section{Participants}

Of 245 patients identified to participate, 150 completed the questionnaire and were analysed: $69(46 \%)$ axSpA, 63 (42\%) RA, 18 (12\%) PsA. Mean age was 48.6 years (SD 17.1), mean disease duration 11.7 (SD 10.1 ) years; $60 \%$ were women (Table 1 ). In all, $69 \%$ used bDMARDs; disease activity was moderate (Table 1). 
Table 1

Description of the 150 patients with inflammatory arthritis

\section{Characteristic}

Age (years), mean (SD)

Women, $\mathrm{N}(\%)$

Disease duration (years), mean (SD)

BMI $(\mathrm{kg} / \mathrm{m} 2)$, mean (SD)

Working status, paid activity, N (\%)

bDMARDs use, $\mathrm{N}(\%)$

Comorbidities: Functional Comorbidity Index (0-18), mean (SD)

mHAQ (0-3), mean (SD)

Disease activity score, mean (SD)

- $\operatorname{axSpA}, \mathrm{N}=69$ : BASDAI $(0-10)$

- In RA (DAS28, 0.96-8.47)

- In PsA (DAPSA, 0- >165)

BMI: Body Mass Index, axSpA: axial SpondyloArthritis, RA: rheumatoid arthritis, PsA: psoriatic arthritis, SD: standard deviation, BASDAI: Bath Ankylosing Spondylitis Disease Activity Index, DAS28: Disease Activity Score, DAPSA: Disease activity in psoriatic arthritis, mHAQ: Modified Health Assessment Questionnaire

\section{Barriers and facilitators}

The mean score of the IFAB questionnaire was 6.0 (SD 19.2), median was 4 (Fig. 1). The two most frequent barriers or facilitators were item 1 (presence or absence of symptoms, $n=111,74 \%$ ) and item 9 (knowledge that physical activity is good for my health, $n=110,73 \%$ ). A total of $39(26 \%)$ patients scored less than -5 and thus could justify a targeted intervention. The IFAB score was slightly negatively associated with physical function; and furthermore, with disease activity only for patients with psoriatic arthritis (online supplementary table 1). Multivariate analyses showed correlation between the IFAB score and number of comorbidities (estimate 3.6, $p<0.05$ ), and physician global assessment (estimate $-2.0, p$ $<0.03)$.

\section{Physical activity behaviors}

Self-reported physical activity through IPAQ-S was moderate (although in the high range of the moderate category; i.e., between 600 and 3000): the mean MET-minutes per week was 2,837 (2,668), median 1,784 (Fig. 2). Level of physical activity was high for $38 \%$ of the participants, moderate for $46 \%$ and low for $16 \%$. In all, $56(37 \%)$ patients reported having the feeling of doing enough activity, and $82(54 \%)$ reported 
following the WHO recommendations for physical activity (54\%) (stage of behavior: action and maintenance).

Physical activity was low when collected by smartphone through mean daily steps per month: mean 5,600 (SD 3,797), median 4578 with $27 \%$ walking over 7,000 steps per day (Fig. 2).

The IPAQ-S was slightly though statistically correlated to steps per day (rho $0.28, p<0.0001$ ), and stage of behavior (rho $0.21, \mathrm{p}<0.001$ ) and was significantly higher in patients who felt sufficiently active (METminutes per week 4,092 (SD 3,210) vs 2,104 (SD 1954), $p<0.0001$ ).

\section{Link between the IFAB questionnaire and physical activity behaviors}

Univariate associations: The global score of the IFAB questionnaire was linked with 3 of the 4 parameters of physical activity: IPAQ-S (rho 0.28, $p<0.001$ ), stage of behavior change (rho $0.35, p<0.001$ ) and the IFAB score was significantly higher in patients who felt sufficiently active: 13.9 (SD 16.2) vs 1.3 (SD 19.4), $p<0.0001)$ (Table 2). However, there was no correlation with steps on smartphones (Table 2). 
Table 2

correlation between IFAB questionnaire, each items and level of physical activity with or without extreme values

\begin{tabular}{|c|c|c|c|c|c|c|}
\hline Item & $\begin{array}{l}\text { Correlation } \\
\text { with IPAQ-S } \\
\text { MET- } \\
\text { minutes } \\
\text { per week, } \\
\text { tho }\end{array}$ & $\begin{array}{l}\text { Score among } \\
\text { patients not } \\
\text { feeling } \\
\text { enough } \\
\text { active, mean } \\
\text { (SD) }\end{array}$ & $\begin{array}{l}\text { Score } \\
\text { among } \\
\text { patients } \\
\text { feeling } \\
\text { enough } \\
\text { active, mean } \\
\text { (SD) }\end{array}$ & $\begin{array}{l}\text { P value } \\
\text { feeling } \\
\text { of } \\
\text { enough } \\
\text { PA }\end{array}$ & $\begin{array}{l}\text { Correlation } \\
\text { with stage } \\
\text { of } \\
\text { behavior } \\
\text { change, } \\
\text { rho }\end{array}$ & $\begin{array}{l}\text { Correlation } \\
\text { with mean } \\
\text { daily steps } \\
\text { per month, } \\
\text { tho }\end{array}$ \\
\hline $\begin{array}{l}\text { Total IFAB } \\
\text { score }\end{array}$ & $0.28 * \star *$ & 1.3 (19.4) & $13.9(16.2)$ & $\star \star \star *$ & $0.35 * * *$ & 0.08 \\
\hline Item 1 & $0.29 * \star \star$ & $-3.1(4.9)$ & $0.3(5.2)$ & $\star \star \star *$ & 0.16 * & 0.16 * \\
\hline Item 2 & 0.06 & $-0.1(4.3)$ & $-1.4(3.8)$ & - & 0.02 & 0.05 \\
\hline Item 3 & 0.08 & $1.1(4.9)$ & $2.0(4.3)$ & - & 0.16 * & 0.01 \\
\hline Item 4 & 0.13 & $1.5(3.7)$ & $2.2(3.6)$ & - & 0.09 & -0.07 \\
\hline Item 5 & -0.09 & $-1.3(2.5)$ & $-0.9(2.4)$ & - & 0.10 & 0.07 \\
\hline Item 6 & 0.22 ** & $-4.27(3.4)$ & $-2.0(2.7)$ & $\star \star \star \star$ & $0.25 * \star \star$ & -0.05 \\
\hline Item 7 & 0.22 ** & $-2.5(3.2)$ & $-0.8(2.4)$ & $\star \star \star *$ & $0.20 * \star$ & 0.12 \\
\hline Item 8 & 0.16 * & $4.7(3.6)$ & $5.9(3.7)$ & - & $0.26 * \star \star$ & 0.11 \\
\hline Item 9 & 0.15 & $4.1(3.8)$ & $5.6(3.7)$ & * & $0.33 * \star \star$ & 0.11 \\
\hline Item 10 & 0.09 & $2.3(3.6)$ & $2.9(3.7)$ & - & 0.17 * & 0.02 \\
\hline $\begin{array}{l}\text { Social } \\
\text { support } \\
\text { subgoup }\end{array}$ & 0.14 & $2.7(7.0)$ & $4.0(6.5)$ & - & $0.27 * \star \star$ & -0.03 \\
\hline $\begin{array}{l}\text { Psychological } \\
\text { and } \\
\text { knowledge } \\
\text { status } \\
\text { subgroup }\end{array}$ & 0.22 ** & 3.0 (11.9) & $10.8(10.7)$ & $\star \star \star *$ & 0.16 * & 0.09 \\
\hline
\end{tabular}

SD: Standard Deviation, PA: physical activity, Social support subgroup = items 3 and 4, Psychological and knowledge status subgroup $=$ items 5 to 10 .

Footnote: $Y$ axis: effectifs, $X$ axis: IFAB score (possible values from - 70 to 70 )

Multivariable analyses confirmed the link between the global score of the IFAB questionnaire and physical activity through IPAQ-S (beta estimate 1.8 for 1000 MET-minutes per week, $p<0.001$ ) and stage of behavior change (beta estimate $4.4, p<0.001$ ). 


\section{Discussion}

In this population, we observed a link between a global score of barriers and facilitators and physical activity levels collected through IPAQ-S. A correlation was also observed in stage of behavior regarding active lifestyle and patients reported less barriers and/or more facilitators when feeling enough active. This study failed to show a correlation between barriers and facilitators and mean daily steps per month collected through patients' smartphones. This questionnaire could be a practical tool to use in clinical practice and in research. Addressing perceived barriers and facilitators to physical activity by using the IFAB questionnaire may therefore be key to increasing the physical activity levels of IA patients.

This study has strength and weaknesses. We observed a correlation of barriers and facilitators with selfreported physical activity but not with mean daily steps per month. This could be explained the fact that a wide variety of physical activities are not covered by steps per day through smartphone, such as swimming or arm movement[39]. A substantial part of the physical activity can be related to domestic activity such as gardening or cleaning. These activities are generally not well captured by the smartphone as steps, leading to an unrepresentative measure of physical activity[40]. In this study, only $61 \%$ of patients included had analysable data. This exclusion rate is due to participant recruitment methods related with the difficulty of using the electronic form. The demographics of the study sample, such as being mainly White, middle class women, limits the generalizability of the findings. This study included IA patients through 3 different conditions (axSpA, RA, PsA). These 3 conditions are the most prevalent inflammatory joint and spine diseases. They share common characteristics such as pain and fatigue, swelling in the joints or axial stiffness, systemic manifestations and can potentially lead to structural changes in joint or spine with loss of function[41, 42]. This study used a validated questionnaire providing a global score.

In our study, we found that barriers that were most correlated with all parameters of self-reported physical activity were items related to physical condition (i.e., symptoms). This correlation was also observed in a cross-sectional study of Suh 2019 including 245 RA patients, where the 18-item Barriers to Health Activities Scale (BHAS) was compared with physical activity self-reported through IPAQ[43], and in Freid et al in 2020 including 108 IA patients[44]. C

In this study, a majority of patients with inflammatory arthritis reported a moderate to low level of physical activity (62\%) and only $37 \%$ patients reported having the feeling of doing enough activity. The mean daily steps per month collected with apps was low $(5,600$; SD 3,797$)$ with $27 \%$ walking over 7,000 steps per day[34,35]. This means that only a minority of people with IA are undertaking the recommended amount of physical activity (7,000 steps per day) and are at risk of complications.

The low level of physical activity observed in this study is coherent with other studies[6,45,46]. This is a major health concern as physical activity is associated with a decrease of cardiovascular risk, a decrease of disease activity and an increase of physical function[8-11]. 
A quarter of patients (26\%) scored less than -5 on the IFAB questionnaire (the lower $25 \%$ of the group) and could justify targeted intervention. The first most frequent barriers or facilitators was the presence or absence of symptoms. Indeed, symptoms such as pain, fatigue and stiffness are highly prevalent in IA patients and lead to disability. Controlling symptoms might be a relevant strategy to enable regular physical activity. The second most reported determinant of physical activity was the knowledge that physical activity is good for health. This item was correlated with stage of behavior change and the feeling of being enough active (but not with IPAQ-S and mean daily steps per week) and could be an easy target to modify through patient education. This underlines the importance of physical activity education and its health benefits.

Similar results were observed in other studies. Brittain et al in 2011 examined in 248 women with arthritis the link between barrier categories and participation in moderate physical activity[22]. They concluded that both arthritis-specific and general barrier limitations were the strongest predictors of self-reported moderate activity. This study did not consider the implication of facilitators in participation to physical activity and did not use a global score. This link between arthritis-specific, general barrier and selfreported moderate activity (GPAQ questionnaire) was also observed in a cross-sectional study of 96 RA patient[21].

In 2002, Bell et al studied in a cross-sectional study of 137 patients with inflammatory joint disease the link between physical activity objectively measured with thigh worn physical activity monitor and exercise believe questionnaire[23]. They observed that attending an exercise facility in the community and low role limitations due to physical health predicted low physical activity. Following the physical activity guideline was linked with low role limitations due to emotional problems, higher physical fitness and healthier exercise attitudes and beliefs.

In conclusion, perceived barriers and facilitators to physical activity were correlated with physical activity, indicating that targeting patients with high barriers and low facilitators to physical activity could be an effective option to improve physical activity levels. Addressing perceived barriers and facilitators to physical activity by using the IFAB questionnaire may be key to increasing the physical activity levels of IA patients.

\section{Declarations}

Funding: This work was supported by Eli Lilly France, Sandoz France and the French Society of Physiotherapy through unrestricted grants. The funders played no role in the design of the study, data collection and analysis, the decision to publish, or the preparation of the manuscript.

Conflicts of interest/Competing interests: Thomas Davergne, Rawdha Tekaya, Camille Deprouw, Jérémie Sellam, Anne Tournadre, Stéphane Mitrovic, Adeline Ruyssen-Witrand, Christophe Hudry, Sabrina Dadoun, Jérôme Avouac, Laure Gossec declare that they have no relevant disclosures. Bruno Fautrel has received research grants from AbbVie, Lilly, MSD and Pfizer, and consultancy fees from AbbVie, Amgen, Biogen, 
BMS, Celgene, Celltrion, Fresenius Kabi, Gilead, Janssen, Lilly, Medac, MSD, Mylan, NORDIC Pharma, Novartis, Pfizer, Roche, Sandoz, Sanofi-Genzyme, SOBI, UCB.

Ethics approval: All procedures performed in studies involving human participants were in accordance with the ethical standards of the institutional and/or national research committee and with the 1964 Helsinki Declaration and its later amendments or comparable ethical standards. The validation study was accepted by the ethics committee (CPP Sud-Est III, France, EudraCT 2019-A01413-54, methodology MR03 for non-interventional study).

Consent to participate: Informed consent was obtained from all individual participants included in the study.

Availability of data and material: The datasets generated during and/or analysed during the current study are available from the corresponding author on reasonable request.

Code availability: The codes used in R software during the current study are available from the corresponding author on reasonable request.

Authors' contributions: All authors contributed to the study conception and design. Material preparation, data collection and analysis were performed by Thomas Davergne and Laure Gossec. The first draft of the manuscript was written by Thomas Davergne and Laure Gossec and all authors commented on previous versions of the manuscript. All authors read and approved the final manuscript.

Acknowledgements. We thank the following coinvestigators: Sylvie Rozenberg, Beatrice Banneville, Rachida Inaoui, Emmanuelle Dernis, Athan Baillet and Catherine Beauvais, and we thank Hervé Servy for expert CRO advice.

\section{References}

1. WHO. Global action plan on physical activity 2018-2030: more active people for a healthier world. WHO. 2018. http://www.who.int/ncds/prevention/physical-activity/global-action-plan-20182030/en/. Accessed 22 Sep 2020.

2. Almeida OP, Khan KM, Hankey GJ, Yeap BB, Golledge J, Flicker L. 150 minutes of vigorous physical activity per week predicts survival and successful ageing: a population-based 11-year longitudinal study of 12201 older Australian men. British Journal of Sports Medicine. 2014;48:220-5.

3. Orrow G, Kinmonth A-L, Sanderson S, Sutton S. Effectiveness of physical activity promotion based in primary care: systematic review and meta-analysis of randomised controlled trials. BMJ. 2012;344:e1389.

4. Evenson KR, Wen F, Herring AH. Associations of Accelerometry-Assessed and Self-Reported Physical Activity and Sedentary Behavior With All-Cause and Cardiovascular Mortality Among US Adults. Am J Epidemiol. 2016;184:621-32. 
5. Kahn EB, Ramsey LT, Brownson RC, Heath GW, Howze EH, Powell KE, et al. The effectiveness of interventions to increase physical activity. A systematic review. Am J Prev Med. 2002;22 4 Suppl:73107.

6. O’Dwyer T., Rafferty T., O’Shea F., Gissane C., Wilson F. Physical activity guidelines: is the message getting through to adults with rheumatic conditions? Rheumatology. 2014;53:1812-7.

7. Sinnathurai P, Capon A, Buchbinder R, Chand V, Henderson L, Lassere M, et al. Cardiovascular risk management in rheumatoid and psoriatic arthritis: online survey results from a national cohort study. BMC Rheumatology. 2018;2:25.

8. Peters MJL, Symmons DPM, McCarey D, Dijkmans B a. C, Nicola P, Kvien TK, et al. EULAR evidencebased recommendations for cardiovascular risk management in patients with rheumatoid arthritis and other forms of inflammatory arthritis. Annals of the Rheumatic Diseases. 2010;69:325-31.

9. Heijde D van der, Ramiro S, Landewé R, Baraliakos X, Bosch FV den, Sepriano A, et al. 2016 update of the ASAS-EULAR management recommendations for axial spondyloarthritis. Annals of the Rheumatic Diseases. 2017;76:978-91.

10. Wendling D, Lukas C, Prati C, Claudepierre P, Gossec L, Goupille P, et al. 2018 update of French Society for Rheumatology (SFR) recommendations about the everyday management of patients with spondyloarthritis. Joint Bone Spine. 2018;85:275-84.

11. Cook MJ, Bellou E, Bowes J, Sergeant JC, O’Neill TW, Barton A, et al. The prevalence of co-morbidities and their impact on physical activity in people with inflammatory rheumatic diseases compared with the general population: results from the UK Biobank. Rheumatology (Oxford). 2018;57:2172-82.

12. Liff MH, Hoff M, Fremo T, Wisløff U, Thomas R, Videm V. Cardiorespiratory fitness in patients with rheumatoid arthritis is associated with the patient global assessment but not with objective measurements of disease activity. RMD Open. 2019;5:e000912.

13. Niedermann K, Nast I, Ciurea A, Vlieland TV, Bodegom-Vos L van. Barriers and Facilitators of Vigorous Cardiorespiratory Training in Axial Spondyloarthritis: Surveys Among Patients, Physiotherapists, and Rheumatologists. Arthritis Care \& Research. 2019;71:839-51.

14. Knittle K, De Gucht V, Hurkmans E, Peeters A, Ronday K, Maes S, et al. Targeting motivation and selfregulation to increase physical activity among patients with rheumatoid arthritis: a randomised controlled trial. Clin Rheumatol. 2015;34:231-8.

15. Kanavaki AM, Rushton A, Efstathiou N, Alrushud A, Klocke R, Abhishek A, et al. Barriers and facilitators of physical activity in knee and hip osteoarthritis: a systematic review of qualitative evidence. BMJ Open. 2017;7:e017042.

16. Belsi A, Papi E, McGregor AH. Impact of wearable technology on psychosocial factors of osteoarthritis management: a qualitative study. BMJ Open. 2016;6:e010064.

17. Martin Ginis KA, Ma JK, Latimer-Cheung AE, Rimmer JH. A systematic review of review articles addressing factors related to physical activity participation among children and adults with physical disabilities. Health Psychol Rev. 2016;10:478-94.

18. Rimmer JH, Marques AC. Physical activity for people with disabilities. The Lancet. 2012;380:193-5. 
19. Davergne T, Moe RH, Fautrel B, Gossec L. Thu0716-Hpr Major Barriers and Facilitators to Physical Activity in Rheumatoid Arthritis Are Related to Physical and Psychological Health, Setting and Social Environmental Factors: A Systematic Literature Review. Annals of the Rheumatic Diseases. 2019;78 Suppl 2:654-5.

20. Davergne T, Moe RH, Fautrel B, Gossec L. Development and initial validation of a questionnaire to assess facilitators and barriers to physical activity for patients with rheumatoid arthritis, axial spondyloarthritis and/or psoriatic arthritis. Rheumatol Int. 2020;40:2085-95.

21. Tan XL, Pugh G, Humby F, Morrissey D. Factors associated with physical activity engagement among adults with rheumatoid arthritis: A cross-sectional study. Musculoskeletal Care. 2019;17:163-73.

22. Brittain DR, Gyurcsik NC, McElroy M, Hillard SA. General and Arthritis-Specific Barriers to Moderate Physical Activity in Women With Arthritis. Women's Health Issues. 2011;21:57-63.

23. Bell K, Hendry G, Steultjens M. Physical activity and sedentary behaviour in people with inflammatory joint disease: a cross sectional study. Arthritis Care \& Research. 2020;n/a n/a. doi:https://doi.org/10.1002/acr.24438.

24. Davergne T, Tekaya R, Deprouw C, Sellam J, Tournadre A, Mitrovic S, et al. To apply the recent EULAR recommendations, more knowledge on adherence patterns to medication and to physical activity is needed. Joint Bone Spine. 2021;88:105137.

25. von Elm E, Altman DG, Egger M, Pocock SJ, Gøtzsche PC, Vandenbroucke JP. The Strengthening the Reporting of Observational Studies in Epidemiology (STROBE) statement: guidelines for reporting observational studies. Journal of Clinical Epidemiology. 2008;61:344-9.

26. Rudwaleit M, Heijde D van der, Landewé R, Listing J, Akkoc N, Brandt J, et al. The development of Assessment of SpondyloArthritis international Society classification criteria for axial spondyloarthritis (part II): validation and final selection. Annals of the Rheumatic Diseases. 2009;68:777-83.

27. Aletaha D, Neogi T, Silman AJ, Funovits J, Felson DT, Bingham CO, et al. 2010 Rheumatoid arthritis classification criteria: An American College of Rheumatology/European League Against Rheumatism collaborative initiative. Arthritis \& Rheumatism. 2010;62:2569-81.

28. Taylor W, Gladman D, Helliwell P, Marchesoni A, Mease P, Mielants H. Classification criteria for psoriatic arthritis: Development of new criteria from a large international study. Arthritis \& Rheumatism. 2006;54:2665-73.

29. Lee PH, Macfarlane DJ, Lam T, Stewart SM. Validity of the international physical activity questionnaire short form (IPAQ-SF): A systematic review. Int J Behav Nutr Phys Act. 2011;8:115.

30. IPAQ scoring protocol - International Physical Activity Questionnaire. https://sites.google.com/site/theipaq/scoring-protocol. Accessed 16 Dec 2020.

31. Marcus BH, Selby VC, Niaura RS, Rossi JS. Self-efficacy and the stages of exercise behavior change. Res Q Exerc Sport. 1992;63:60-6.

32. Case MA, Burwick HA, Volpp KG, Patel MS. Accuracy of Smartphone Applications and Wearable Devices for Tracking Physical Activity Data. JAMA. 2015;313:625-6. 
33. Duncan MJ, Wunderlich K, Zhao Y, Faulkner G. Walk this way: validity evidence of iphone health application step count in laboratory and free-living conditions. J Sports Sci. 2018;36:1695-704.

34. Tudor-Locke C, Craig CL, Aoyagi Y, Bell RC, Croteau KA, De Bourdeaudhuij I, et al. How many steps/day are enough? For older adults and special populations. Int J Behav Nutr Phys Act. 2011;8:80.

35. Tudor-Locke C, Craig CL, Thyfault JP, Spence JC. A step-defined sedentary lifestyle index: $<5000$ steps/day. Appl Physiol Nutr Metab. 2013;38:100-14.

36. Groll DL, To T, Bombardier C, Wright JG. The development of a comorbidity index with physical function as the outcome. J Clin Epidemiol. 2005;58:595-602.

37. Prevoo ML, van 't Hof MA, Kuper HH, van Leeuwen MA, van de Putte LB, van Riel PL. Modified disease activity scores that include twenty-eight-joint counts. Development and validation in a prospective longitudinal study of patients with rheumatoid arthritis. Arthritis Rheum. 1995;38:44-8.

38. Schoels MM, Aletaha D, Alasti F, Smolen JS. Disease activity in psoriatic arthritis (PsA): defining remission and treatment success using the DAPSA score. Annals of the Rheumatic Diseases. 2016;75:811-8.

39. Bassett DR, Toth LP, LaMunion SR, Crouter SE. Step Counting: A Review of Measurement Considerations and Health-Related Applications. Sports Med. 2017;47:1303-15.

40. Westerterp KR. Assessment of physical activity: a critical appraisal. Eur J Appl Physiol. 2009;105:823-8.

41. Feld J, Chandran V, Haroon N, Inman R, Gladman D. Axial disease in psoriatic arthritis and ankylosing spondylitis: a critical comparison. Nature Reviews Rheumatology. 2018;14:363.

42. Schett G, Gravallese E. Bone erosion in rheumatoid arthritis: mechanisms, diagnosis and treatment. Nature Reviews Rheumatology. 2012;8:656-64.

43. Suh $\mathrm{C}-\mathrm{H}$, Jung $\mathrm{J}-\mathrm{Y}, \mathrm{Oh} \mathrm{H}$, Boo S. Evaluation of factors affecting the levels of physical activity in patients with rheumatoid arthritis: a cross-sectional study. Clin Rheumatol. 2019;38:2483-91.

44. Freid LM, Ogdie A, Baker JF. Physical Activity Patterns in People With Inflammatory Arthritis Indicate They Have not Received Recommendation-Based Guidance From Health Care Providers. ACR Open Rheumatology. 2020;2:582-7.

45. Swinnen TW, Scheers T, Lefevre J, Dankaerts W, Westhovens R, Vlam KL de. Physical Activity Assessment in Patients with Axial Spondyloarthritis Compared to Healthy Controls: A TechnologyBased Approach. In: PloS one. 2014.

46. Jacquemin C, Servy H, Molto A, Sellam J, Foltz V, Gandjbakhch F, et al. Physical Activity Assessment Using an Activity Tracker in Patients with Rheumatoid Arthritis and Axial Spondyloarthritis:

Prospective Observational Study. JMIR mHealth and uHealth. 2018;6:e1.

\section{Figures}




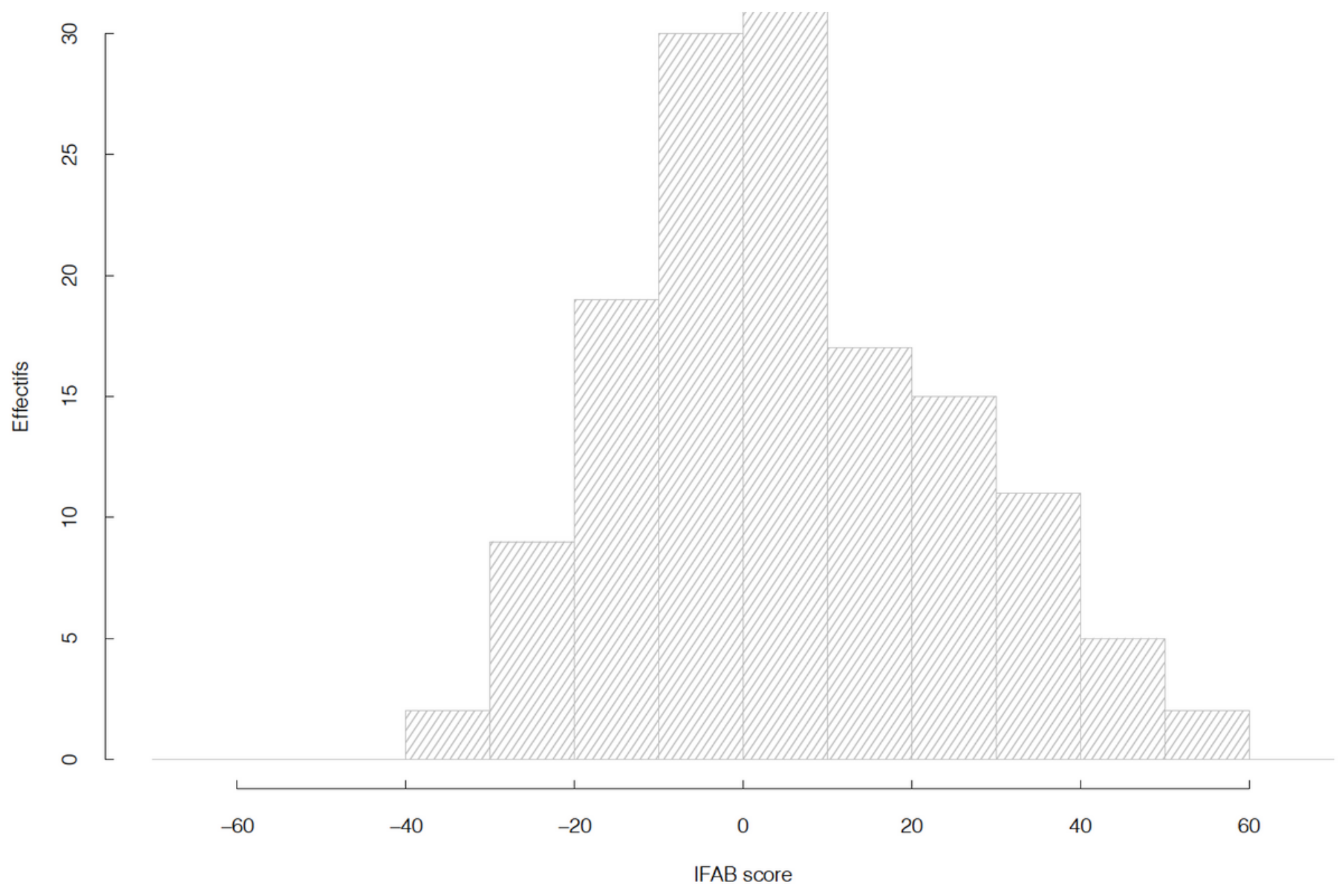

\section{Figure 1}

Distribution of the IFAB score measuring barriers and facilitators to physical activity in 150 patients with inflammatory arthritis. Footnote: $Y$ axis: effectifs, $X$ axis: IFAB score (possible values from -70 to 70 ) 


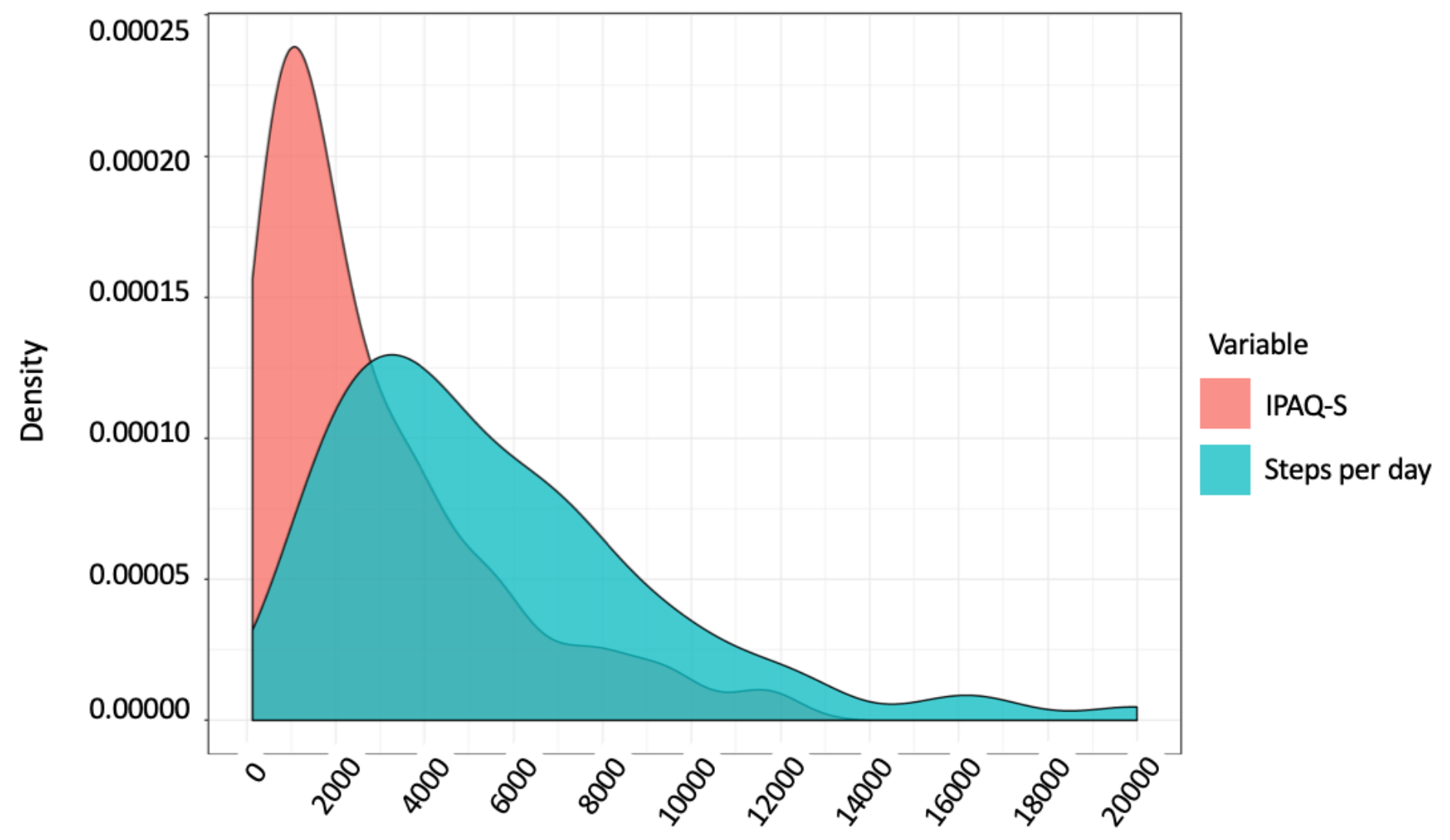

Figure 2

distribution of the IPAQ-S score and mean daily steps per month in 150 patients. Footnote X-axis: METminutes per week (IPAQ-S) for the red curve, mean daily steps per month (steps) for the blue curve. $Y$ axis= Density

\section{Supplementary Files}

This is a list of supplementary files associated with this preprint. Click to download.

- ImBAIABMCOnlinesupplementary.docx 